\title{
Ensino e aprendizagem de línguas mediado por computador: conectando teoria e prática em um jogo ${ }^{1}$
}

\section{Computer assisted language learning and teaching: connecting theory and practice in a game}

\author{
Susana Cristina dos Reis* \\ Rosangela Segala de Souza** \\ Adilson Fernandes Gomes***
}

RESUMO: Este artigo reporta a experiência de construção de materiais digitais para um curso de língua inglesa mediado por computador, utilizando ambientes virtuais de ensino-aprendizagem e simuladores de mundos virtuais para propor atividades em LI. Os resultados sugerem que a construção de materiais digitais, bem como os desafios que envolvem articular conhecimentos interdisciplinares exigem a formação de uma equipe multidisciplinar, que conecte conhecimentos tecnológicos com pressupostos teórico-metodológicos sobre ensino de línguas e jogos sérios, para garantir o desenvolvimento do projeto em andamento.

PALAVRAS-CHAVE: Material didático digital; Ambiente imersivo; Ensino de LI; Conhecimento interdisciplinar.

\begin{abstract}
This article reports an experience of constructing digital materials to a computer assisted language learning course, using virtual worlds and a learning management system to propose English Language activities. The results suggest that the development of digital material following games principles and interdisciplinary activities in English as Foreign Language require an interdisciplinary work-team articulating theoretical and methodological awareness about language teaching and serious games, as well as technological skills to ensure good game development principles.
\end{abstract}

KEYWORDS: Digital learning material; Immersive environment; English teaching; Interdisciplinary knowledge.

\section{Introdução}

O uso da Web 2.0 tem ocasionado a possibilidade de ampliação dos processos de ensino-aprendizagem por meio de tecnologias, especialmente para a prática de ensino de línguas online, incluindo diferentes ferramentas e gêneros digitais nesses processos. Em

${ }^{1}$ Trabalho desenvolvido no GRPesq/CNPq Núcleo de Pesquisa, Ensino e Aprendizagem de Línguas a Distância (NUPEAD) - UFSM;

* Professora Adjunto 1, no Curso de Letras/UFSM/NTE; Coordenadora do Núcleo de Pesquisa, Ensino e Aprendizagem de Línguas a Distância (NUPEAD) - suzireis@nte.ufsm.br;

** Professora do Instituto Federal Farroupilha (IFF), Campus São Vicente do Sul, integrante do Núcleo de Pesquisa, Ensino e Aprendizagem de Línguas a Distância (NUPEAD) - rosegalasm@gmail.com;

*** Acadêmico do Curso de Letras Licenciatura Habilitação em Inglês e Literatura inglesa (UFSM), integrante do Núcleo de Pesquisa, Ensino e Aprendizagem de Línguas a Distância (NUPEAD) adilson.fernandesgomes@gmail.com. 
particular, por meio da Internet, alunos podem acessar remotamente materiais didáticos digitais (doravante MDD) elaborados em diversas plataformas e, também, realizar atividades colaborativas, estabelecendo interações que podem reduzir alguns dos efeitos negativos geralmente gerados em cursos a distância.

Tendo em vista desenvolver projetos, na área de ensino de línguas mediado por computador, que incluam tecnologias interativas e princípios de jogos sérios (ou serious games), um dos projetos em desenvolvimento no Grupo de Pesquisa - GRPesq - Núcleo de Pesquisa, Ensino e Aprendizagem de Línguas a Distância - é o curso de inglês mediado por tecnologias digitais - English Online 3D (E-3D).

O projeto English Online $3 D$ (E-3D) é um curso online que faz uso do ambiente virtual de ensino-aprendizagem - Moodle - e do ambiente imersivo em 3D - o simulador OpenSim - para ensinar conteúdos de língua inglesa (doravante LI), em nível préintermediário. Ao elaborarmos o ambiente do curso E-3D, optamos por construir o MDD do curso seguindo princípios de jogos sérios (GEE, 2004; JOHNSON, 2005), já que o públicoalvo do curso serão alunos que estão na faixa etária entre 15 e 25 anos.

Ao planejarmos as atividades do curso E-3D, iniciamos a construção de atividades/tarefas de LI que serão realizadas por meio de uma cidade fictícia criada no OpenSim, para que os alunos ao interagirem, em diferentes situações comunicativas, se sentissem desafiados para aprender a língua-alvo de modo interdisciplinar.

Para desenvolver esse projeto, em parceria com a equipe do LabInter ${ }^{2}$, começamos a estruturar as fases do jogo, o qual nomeamos de Inglês em Ambientes Imersivos Interativos e Interdisciplinares em $3 D$ ou I-AI3. Neste artigo, descrevemos o processo de construção do jogo I-AI3, dando ênfase nas fases que foram elaboradas para a prática da LI, bem como para a discussão de conteúdos sobre educação ambiental. Vale ressaltar que o jogo I-AI3 constituise no principal MDD encontrado no curso E-3D. Além disso, tanto o jogo quanto o curso estão em fase inicial de desenvolvimento.

Este artigo está dividido em três seções, sendo que a primeira aborda brevemente o foco das pesquisas na área de ensino e aprendizagem de línguas mediado por computador, especialmente no Brasil sobre material didático; a segunda discute pressupostos teóricos-

\footnotetext{
${ }^{2}$ LabInter - Laboratório Interdisciplinar Interativo - localizado no Centro de Artes e Letras, na UFSM, desenvolve diferentes projetos que envolvem pesquisas interativas, interdisciplinares e colaborativas e faz uso de realidade virtual, ambientes virtuais de aprendizagem e ambientes imersivos em 3D para ensinar diferentes conteúdos (OLIVEIRA et al., 2012).
} 
metodológicos sobre ensino de línguas que orientam a construção do curso English 3D e do Jogo I-AI3; a terceira, por fim, propõe as considerações finais.

\section{Pesquisas na área de Ensino e Aprendizagem de línguas mediado por computador no Brasil: foco na produção de materiais didáticos digitais}

A área de ensino de línguas mediado por computador é um campo de investigação muito novo no Brasil, tendo em vista que faz pouco mais de uma década que os estudos em Linguística Aplicada (LA) incluem em suas pesquisas o uso de tecnologias digitais (REIS, 2010).

Nas pesquisas em LA, mais especificamente, na última década, vários estudos têm se preocupado em discutir a inserção de tecnologias nas aulas de línguas estrangeiras, a exemplo das obras de Paiva (2001a), Marcuschi e Xavier (2004), Collins e Ferreira (2004), Araújo (2007), entre outros.

Em estudos sobre a análise de publicações que reportam as pesquisas envolvendo a área de ensino mediado por computador, Reis (2010) buscou estabelecer parâmetros de comparação entre os temas que interessam a agenda de pesquisa brasileira e a estrangeira, buscando destacar quais são essas temáticas. Com isso, essa análise evidenciou que os temas abordados nas investigações em $\mathrm{CALL}^{3}$, a produção de material didático digital carece de mais estudos, principalmente no desenvolvimento de pesquisas que alinhem a teoria e a prática.

A temática - elaboração de material didático para o ensino online - passou a fazer parte de algumas pesquisas, por exemplo, a tese produzida por Martins Fontes (2002) discutiu as especificidades do meio digital, a interatividade, a estruturação hipertextual e documental de um curso de inglês a distância. Nesse estudo, a autora destacou como essas especificidades do meio eletrônico redimensionam, potencializam e criam ações estratégicas que podem ser extremamente relevantes para o processo de aprendizagem de inglês via Internet, principalmente, para a produção de materiais didáticos digitais que são propostos na forma de cursos online (REIS, 2010, p. 64).

De acordo com Reis (2010, p. 65), a preocupação em analisar os materiais já produzidos e, em exemplificar o uso de tecnologias no ensino de línguas, levou outros

\footnotetext{
${ }^{3}$ CALL é a sigla para Computer Assisted Language Learning, que significa Aprendizagem de línguas mediada por computador.
} 
pesquisadores a investigar os MDD produzidos para o ensino de línguas mediado por computador ou oferecidos na modalidade a distância. Nesse período, o foco das pesquisas passou a ser a descrição de materiais de ensino de línguas estrangeiras para a Internet e seus possíveis usos em sala de aula. Esse tópico instigou o interesse de vários linguístas aplicados, como podemos observar nos estudos de Leffa (2003b), Braga (2004), Vetromille-Castro (2003), Collins e Ferreira (2004), entre outros.

Na pesquisa de Vetromille-Castro (2003), o autor discute algumas alternativas que o professor de línguas pode explorar em suas aulas ou na elaboração de material didático para que as aulas se tornem mais motivadoras e desafiantes aos alunos. Na percepção do autor (Ibidem), as atividades via Internet motivam os alunos a aprender línguas, pois ao interagirem virtualmente, os alunos podem considerar as atividades relevantes para sua interação social, porque o conhecimento passa a ser socializado e compartilhado (REIS, 2010).

Semelhantemente, Leffa (2003a) enfatiza a importância que o computador e a Internet passam a ter no processo de elaboração de material didático, tanto para aulas presenciais quanto para aulas mediadas por computador. Para o autor (Ibidem), por meio de um clique, podemos ter acesso a diversos textos, a diferentes imagens que abordam um mesmo tema, o que pode tornar a elaboração de nosso material didático mais rico, pois o aluno pode ter contato com textos autênticos, que estão à disposição deles na Internet, basta poder acessá-los (REIS, 2010).

Ao pensarmos na elaboração de materiais didáticos para a Internet, devemos considerar o papel do aluno e quais interações ele poderá desenvolver por meio daquele material. A inserção do computador, nas aulas de LE, não garante a resolução de problemas de ordem pedagógica, simplesmente pelo uso dessas ferramentas no contexto escolar. $\mathrm{O}$ uso de computadores e da Internet devem ter um objetivo claro de aprendizagem e isso requer que o docente saiba avaliar e refletir se a ferramenta é adequada (ou não) à sua proposta de ensino e de aprendizagem, bem como para a proposta didático-pedagógica que pretende desenvolver (REIS, 2010).

Sendo assim, parece importante propor MDD que incluam tecnologias variadas, sem perder de vista o desenvolvimento de atividades, levando em consideração as concepções de linguagem que devem orientar tanto a produção do MDD quanto o ensino. Com o objetivo de produzir pesquisa sobre a produção de $\mathrm{MDD}$, neste artigo, reportamos a experiência de construção de um jogo de inglês em 3D que será testado como material didático do Curso 
English Online $3 D$ como contexto de interação para o desenvolvimento da aprendizagem de LI. Na sequência, destacamos os pressupostos teórico-metodológicos que guiam a construção do curso e do jogo.

\section{English Online 3D e o jogo I-AI3: conectando pressupostos teórico-metodológicos}

Originalmente, o English Online $3 D$ é um projeto de ensino a distância que tem por objetivo conectar alunos na Internet, de forma que estes se envolvam em atividades de linguagem por meio de diferentes gêneros digitais (REIS, 2004; 2006; 2010) e tecnologias imersivas com a finalidade de aprender a língua inglesa por meio da interação virtual.

$\mathrm{Na}$ literatura de ensino de língua que tem como base a pedagogia dos gêneros (BAZERMAN, 2005; HYLAND, 2007; MOTTA-ROTH et al., 2007), pesquisadores sugerem que o ensino deve ser orientado por atividades que incluam gêneros discursivos/textuais que possibilitem a interação dos participantes por meio de diferentes práticas sociais, com vistas a desenvolver a aprendizagem por meio da prática e do uso da linguagem (PAIVA, 1999; 2001b). Assim, no curso English Online 3D, buscamos explorar gêneros digitais e discursivos, bem como contextos que levem os alunos à resolução de problemas propostos por meio de atividades de língua inglesa.

Com o propósito de elaborar um jogo adequado às necessidades do curso, decidimos prever nas atividades do Projeto English Online $3 D$ a prática da língua inglesa por meio de um jogo imersivo, que permitisse ao aluno discutir questões relacionadas à educação ambiental e aprimorar seu conhecimento de língua dentro dessa temática. Dessa forma, com o apoio da equipe do LabInter, iniciamos a construção do protótipo do jogo I-AI3 para ser usado pelos participantes do curso.

Tendo em vista desenvolver a aprendizagem crítica no ensino interdisciplinar, buscamos um suporte teórico que atendesse nossas expectativas, pois segundo Gee (2004) todo bom jogo tem por trás uma boa teoria de aprendizagem. Para isso, adotamos alguns princípios que orientam tanto a construção do protótipo quanto a aprendizagem de línguas, que são: a linguagem é uma prática social (HALLIDAY, 1989; MOTTA-ROTH, 2008), portanto precisamos possibilitar que os participantes interajam por meio da linguagem para desenvolver diferentes habilidades linguísticas através do jogo; os participantes devem buscar desenvolver multiletramentos (MOTTA-ROTH; HENDGES, 2010); os conteúdos 
(linguísticos ou de diferentes áreas) devem ser desafiantes (GEE, 2004; JOHNSON, 2005) e hipertextuais para gerar aprendizagem.

O protótipo do jogo I-AI3 está conectado a um mundo virtual em 3D e, para isso, utilizamos o Open Simulator (OPENSIM, 2012) como hospedeiro. Começamos a construir o I-AI3 como um espaço virtual para a colaboração e a construção interdisciplinar, conectando a aprendizagem de língua inglesa com a discussão de questões ecológicas em um único protótipo.

No OpenSim (Figura 1), planejamos, até o presente momento, três fases em que os alunos podem se conectar para jogar e, ao mesmo tempo, aprender a língua inglesa. Os participantes são representados por avatares que usam a língua inglesa para interagir uns com os outros, discutindo sobre questões ecológicas no âmbito urbano.

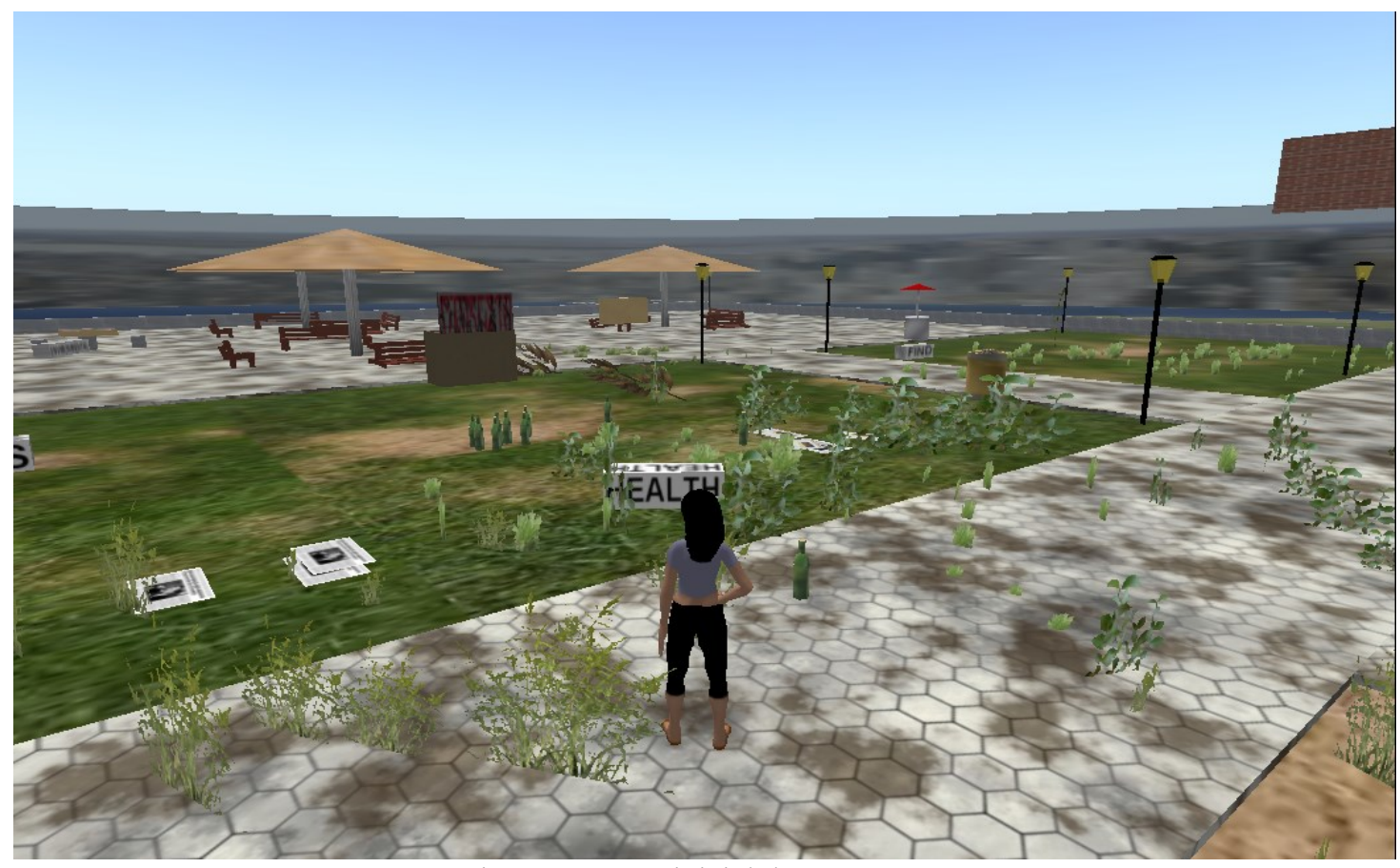

Figura 1. Etapa inicial do Jogo I-AI3

Para elaborar as atividades das três fases do protótipo do jogo imersivo I-AI3, desenvolvemos uma narrativa que situa o participante em um determinado contexto e situação. Nesse ambiente, o participante assume uma identidade digital representada por um avatar, o qual é desafiado a tomar uma decisão para solucionar um problema proposto dentro do contexto social em que está inserido.

De acordo com a solução desse problema, o participante terá uma recompensa que poderá ser um bônus ou um conhecimento linguístico, que lhe favorecerá na execução das 
atividades. Nessa perspectiva, atendemos aos fatores de satisfação que, segundo Johnson (2005), envolvem os participantes no ato de jogar, ou seja, o desafio, a tomada de decisão e a recompensa.

Conforme já enfatizamos em trabalho anterior publicado sobre o jogo I-AI3 (OLIVEIRA et al., 2012), buscamos desenvolver um ambiente virtual que possua características dialógicas, não lineares e interativas para criar diferentes universos significativos. Para isso, é necessário produzir um jogo que faça uso de linguagens híbridas, conectando imagens, som e textos que tenham conexões significativas com o objetivo de aprendizagem (ver Figura 2).

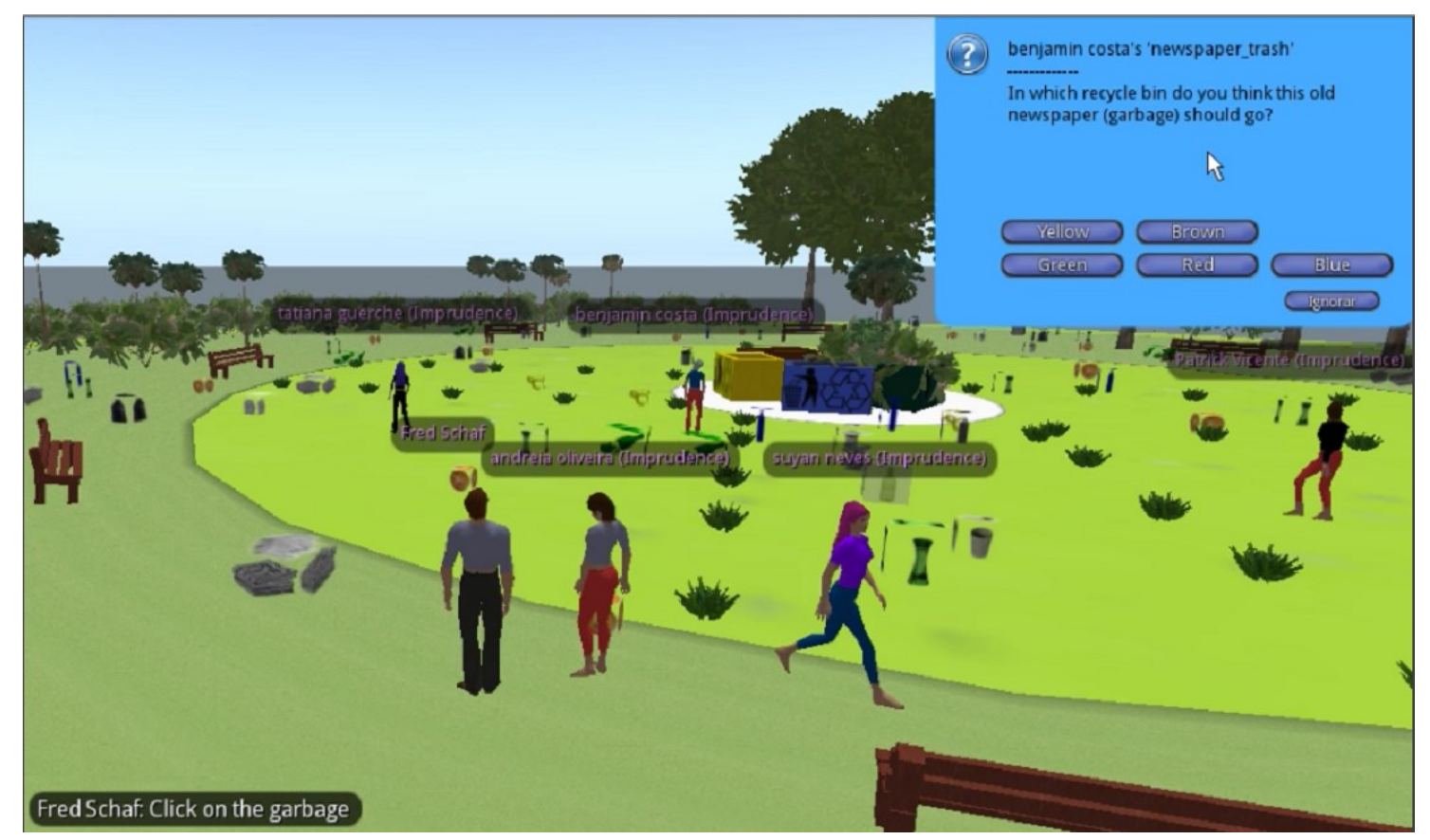

Figura 2. Fase do Jogo I- AI3

Para Bairon (2004), há atualmente na Internet muitas oportunidades para o desenvolvimento de metodologias hipermidiáticas, que permitem ir além da divisão de tarefas, que explorem apenas a leitura e a escrita ou, ainda, a arte (imagem e som) (OLIVEIRA et al., 2012). Temos que considerar a multiplicidade de multimodalidades que se projetam em diferentes ambientes virtuais e que podem se tornar significativas para a aprendizagem de uma língua estrangeira (ver Figura 3). 


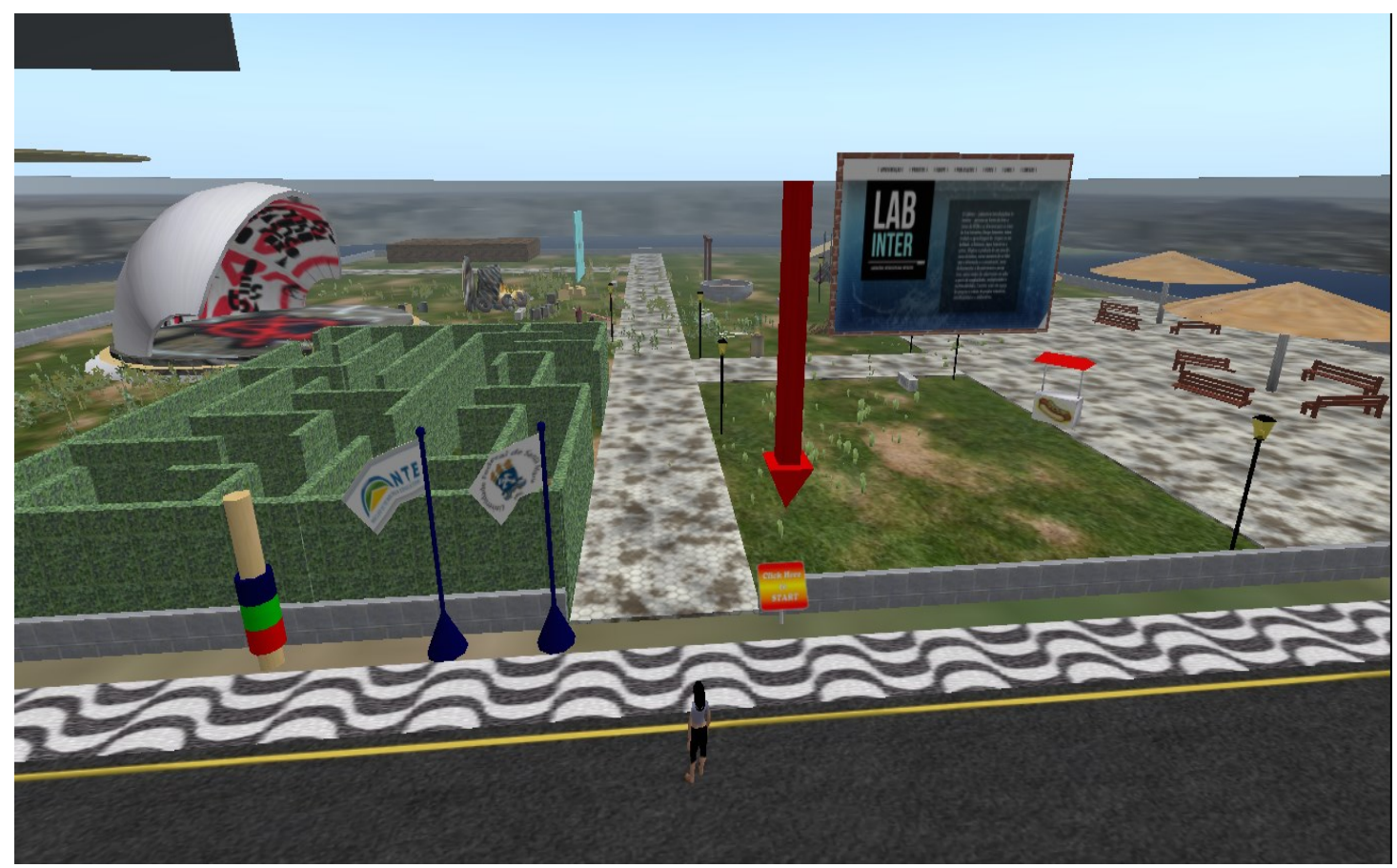

Figura 3. Fase do Jogo I-AI3

Além disso, almejamos desenvolver, por meio dos desafios propostos no jogo, novos letramentos, a partir da inserção dos participantes no uso de gêneros digitais, que possibilitem a aprendizagem dos alunos por meio de hipertextos e de situações hipermidiáticas, as quais simulem situações reais.

\subsection{Os desafios na elaboração da proposta do protótipo do jogo imersivo I-AI3}

O processo interdisciplinar de elaboração do protótipo do jogo está envolvido por uma série de desafios que implicam em conquistas, dificuldades e conflitos, os quais podem ser de ordem teórico-metodológica, bem como do uso da tecnologia.

As dificuldades e os conflitos de ordem teórico-metodológica compreendem em fazer com que todos os membros da equipe fundamentem-se pelo mesmo suporte teórico sobre princípios de jogos, aprendizagem e de conhecimentos linguísticos, mais especificamente, como se concebe o ensino de língua inglesa. Verificamos que as dificuldades geradas aconteciam por envolverem profissionais de diversas áreas do conhecimento (Letras, Artes, Engenharia e Direito), tornando-se extremamente difícil estabelecer um princípio comum, que satisfizesse as exigências de todos. Como o projeto é um só, envolve muita negociação, pois cada profissional tem uma concepção de produção diferente, principalmente, quando estão envolvidas concepções teóricas, que dizem respeito às diferentes áreas disciplinares. 
Para isso, optamos em fazer um levantamento teórico sobre o desenvolvimento de jogos imersivos, tanto em literatura produzida no Brasil quanto no exterior, como uma alternativa para que todos os integrantes da equipe lessem sobre o mesmo assunto e pudessem discutir com mais propriedade sobre esse tema, visto que todos estão envolvidos na elaboração das atividades do projeto do jogo. Foram discutidos temas como: a relação entre o jogo e a aprendizagem, os princípios de aprendizagem incorporados em jogos, aprendizagem crítica (critical learning), que implica aprender ativamente pela prática e pela experiência, formando grupos colaborativos, resolvendo problemas e desenvolvendo estratégias que poderão ser úteis em outras situações, além daquelas em estudo sobre serious games.

Ao elaborarmos as atividades para ensino a distância no jogo I-AI3, foi necessário o cuidado de não apenas fazermos a transposição de materiais didáticos utilizados em sala de aula convencional, mas buscamos criar um ambiente virtual interativo e hipertextual, em que o aluno possa interagir de diferentes formas. No jogo, em que ocorre aprendizagem e entretenimento, a dificuldade de estabelecer essa associação é um dos primeiros desafios enfrentados pela equipe, pois a aprendizagem deve ocorrer de forma sistematizada, mas sem a formalidade de um estudo tradicional e, também, deve estimular o interesse do aprendiz de modo que seja motivado a seguir até o final, superando os desafios do jogo, sem que esse se torne cansativo e enfadonho.

O conflito de ordem tecnológica ocorre tendo em vista que o protótipo I-AI3 está sendo desenvolvido na plataforma Open Simulator e nem todos os integrantes dominam e entendem o funcionamento dessa tecnologia. Os aspectos estudados nesse campo foram a personalização de avatar e a inserção no mundo virtual criado nesse ambiente. Com isso, ter a dimensão das possibilidades e das limitações do OpenSim é algo que envolve estudo e tempo, pois nem sempre o que é desejável ou planejado por um grupo de pesquisadores passa a ser executado em função da falta de conhecimento da tecnologia. Por outro lado, esse processo de planejamento das atividades exige novas negociações e a reorganização das atividades elaboradas.

De modo geral, as dificuldades e os conflitos são benéficos para o projeto, pois sentimos a necessidade de promover um ciclo de palestras semanais, no qual as decisões são negociadas, além de serem debatidos os textos selecionados para a leitura prévia. É oportuno acrescentar, ainda, que esses textos envolvem todas as áreas do LabInter (Letras, Artes e Engenharia) em sistema rotativo de abordagens. As palestras são ministradas pelos integrantes 
dos grupos, visando um nivelamento do conhecimento de forma que todos os integrantes saibam o que cada grupo está lendo. Estabelecemos conceitos-chave para guiar, de modo interdisciplinar, a equipe na elaboração do jogo, principalmente, com relação às concepções sobre o que são jogos educacionais e jogos sérios.

Os conflitos de ordem conceitual, tanto no que se refere aos processos de ensinoaprendizagem quanto aos temas são elementos das discussões afloradas no planejamento, gerados pelos diferentes olhares de cada área possibilitando o enriquecimento do projeto.

\section{Considerações finais}

A tarefa de criar um material didático interativo para o jogo I-AI3, que envolva diferentes áreas do conhecimento, ainda está em fase inicial e necessita de mais estudos. Contudo, verificamos que o protótipo já apresenta algumas potencialidades, tais como: permitir a interação dos alunos em língua inglesa e possibilitar a construção do conhecimento sobre questões ecológicas.

Conforme está previsto no planejamento das fases, nosso objetivo no jogo é levar o aluno a refletir sobre: os diferentes tipos de poluição existentes, como reciclar produtos, bem como quais são os benefícios da reciclagem para o planeta Terra. Além disso, pensamos que a simulação de práticas sociais, por meio do mundo virtual, criado no OpenSim, pode estimular os alunos a refletirem sobre as ações que podem ser realizadas também no mundo real.

Ao jogar, acreditamos que o aluno pode construir, tanto um inventário linguístico, constituído por frases, sentenças, expressões e vocabulário relacionados ao tema meio ambiente, quanto fazer uso desse vocabulário ao interagir em LI com os outros participantes do jogo.

Além disso, acreditamos que a possibilidade de jogar individualmente ou em equipe, com o objetivo de resolver as atividades propostas e desenvolver a consciência ecológica, pode ocasionar que os participantes sejam capazes de agir não apenas no mundo virtual, mas também no mundo real.

A conexão do jogo com o ambiente virtual do curso English Online 3D, por meio do MOODLE - possibilita que o participante tenha acesso a outros contextos de interação, além daqueles previstos no OpenSim. Essa possibilidade contribui para a disponibilização de materiais didáticos extras que poderão servir de suporte linguístico para a resolução dos desafios que os participantes enfrentarão no jogo. 
A elaboração do I-AI3 foi um desafio para a equipe engajada no projeto. O diálogo, a troca de ideias e leituras permitiram que chegássemos até este momento. Muito ainda precisa ser feito, revisado, testado e reorganizado, mas continuamos confiantes de que o projeto alcançará nosso objetivo maior, que é a aprendizagem.

Para isso, temos muito trabalho para realizar até chegarmos à primeira versão final do jogo I-AI3; no entanto, acreditamos que o trabalho em equipe, bem como as avaliações constantes desse processo de construção do material didático em desenvolvimento, poderá resultar em um bom jogo orientado, pelo menos, por bons princípios de aprendizagem.

\section{Referências}

ARAUJO, J. C. Internet e ensino: novos gêneros, outros desafios. São Paulo: Editora Lucerna, 2007.

BAIRON, S. Tendências da Linguagem Científica Contemporânea em expressividade digital: uma problematização. Informática na educação: teoria \& prática. Porto Alegre, v. 7, n. 2, p. 101-156, jul./dez. 2004.

BAZERMAN, C. Gêneros textuais, tipificação e interação. São Paulo: Cortez Editora, 2005.

BRAGA, D. B. Linguagem pedagógica e materiais para aprendizagem independente de leitura na web. In: COLLINS, H.; FERREIRA, A. (Org.). Relatos de experiência de ensino e aprendizagem de línguas na Internet. Campinas: Mercado de Letras, 2004, p. 157-185.

COLLINS, H.; FERREIRA, A. Relatos de ensino e aprendizagem de línguas na Internet. Campinas: Mercado de Letras, 2004.

GEE, J. P. What video games have to teach us about learning and literacy. New York: Palgrave Macmillan, 2004.

HALliDAY, M. A. K. Part A. In: HALLIDAY, M. A. K.; HASAN, R. Language, context and text: Aspects of language in a social-semiotic perspective. Oxford: Oxford University, 1989, p. 3-49.

HYLAND, K. Genre pedagogy: language, literacy and L2 writing instruction. Journal of Second Language Writing, v. 16, p.148-164, 2007.

JOHNSON, S. Surpreendente! A televisão e o videogame nos tornam mais inteligentes. Rio de Janeiro: Editora Campus, 2005. 
LEFFA, V. J. Análise automática da resposta do aluno em ambiente virtual. Revista Brasileira de Linguística Aplicada. Belo Horizonte, v. 3, n. 2, p. 25-40, 2003 a.

.Como produzir materiais para o ensino de línguas. In: LEFFA, V. J. (Org.). Produção de materiais de ensino: teoria e prática. Pelotas: Educat, 2003b, p. 15-41.

MARCUSCHI, L. A.; XAVIER, A. C. Hipertexto e gêneros digitais. 1 ed. Rio de Janeiro: Editora Lucerna, 2004.

MARTINS FONTES, M. C. Aprendizagem de inglês via internet: descobrindo as potencialidades do meio digital. 2002. 217 f. Tese (Doutorado em Linguística Aplicada). LAEL, Pontifícia Universidade Católica (PUC-SP), São Paulo, 2002.

MOTTA-ROTH, D.; REIS, S. C.; MARSCHALL, D. O Gênero página pessoal e o ensino de produção textual em Inglês". In ARAÚJO, J. C. (Org.) Internet e ensino. 1 ed. Rio de Janeiro: Lucerna, 2007, p. 126-143.

MOTTA-ROTH, D. Para ligar a teoria à prática: roteiro de perguntas para orientar a leitura/análise crítica de gênero. In: MOTTA-ROTH, D.; CABAÑAS, T.; HENDGES, G.. (Org.). Análises de textos e de discursos: relações entre teorias e práticas. 1. ed. Santa Maria: PPGL Editores, v. 1, 2008, p. 243-272.

MOTTA-ROTH, D; HENDGES, G. R. Explorando modalidades retóricas sob a perspectiva da multimodalidade. Revista Letras, Universidade Federal de Santa Maria, Programa de PósGraduação em Letras, v. 20, n. 40, p. 43-66, jan./jun. 2010.

OLIVEIRA, A.; REIS, S.C; SCHAF, F. LABINTER - Connecting and creating Interdisciplinary interactive e-learning projects. In: INTERNATIONAL ASSOCIATION FOR DEVELOPMENT OF THE INFORMATION SOCIETY INTERNATIONAL CONFERENCE E-LEARNING, 2012, Proceedings of the IADIS Multiconference on Computer Science and Information Systems (MCCSIS 2012). Anais... Lisboa. 2012. p. 455-459.

OPENSIM. Open Simulator Project Website. Disponível em_http://opensimulator.org. Acesso em 13 Março 2012.

PAIVA, V. L. M. O. (1999) Diários online na aprendizagem de língua inglesa mediada por computador. In: MARI, H.; MACHADO, I. L.; MELLO, R. (Org.) Fundamentos e dimensões da análise do discurso. Belo Horizonte: Carol Borges, 1999, p. 359-378.

. Interação e aprendizagem em ambiente virtual. Belo Horizonte: Faculdade de Letras, UFMG, 2001a.

Aprendendo inglês no ciberespaço. In: PAIVA, V. L. M. O. (Org.). Interação e aprendizagem em ambiente virtual. Belo Horizonte: Faculdade de Letras, UFMG, 2001b, p. 270-305. 
REIS, S. C. A intervenção pedagógica do professor em contextos diferenciados: a oferta de andaimes na aula de inglês presencial e a distância. 2004. 171 f. Dissertação (Mestrado em Estudos Linguísticos), Instituto de Estudos da Linguagem - IEL, Unicamp: Campinas, 2004.

. O chat como um gênero privilegiado para o ensino colaborativo de língua inglesa. In: Linguagens \& Cidadania, v. 6, p. 01-16, 2006. Disponível em http://jararaca.ufsm.br/websites/1\&c/download/Artigos/L\&C 2S 06/SuzanaL\&C2006.pdf. Acesso em 10 agosto 2012.

. Do discurso à prática: textualização de pesquisas sobre ensino de inglês mediado por computador. 2010. 242 f. Tese (Doutorado em Estudos Linguísticos). Programa de Pós-Graduação em Letras da Universidade Federal de Santa Maria, Santa Maria, 2010.

VETROMILLE-CASTRO, R. O professor como facilitador virtual: considerações teóricopráticas sobre a produção de materiais para aprendizagem via web ou mediada por computador. In: LEFFA, V. J. (Org.). Produção de materiais de ensino: teoria e prática. Pelotas: Educat, 2003, p. 125-151.

Artigo recebido em: 15.10 .2012

Artigo aprovado em: 17.12.2012 